\title{
Next Generation Machine Learning for Urban Water Management
}

\author{
Developing Autoflow, a Machine Learning System
}

K Nguyen, R Stewart, H Zhang, C Jones, N Siriwardene, A Brown, A Radion, J Crook, M Stevens, N Smith, D Giurco, M Blumenstein, S Rahim

\section{ABSTRACT}

Determining the end uses of water in residential properties can facilitate a more proactive approach to water literacy, awareness and demand management. This type of information enables the public, government and water businesses to implement more cost-effective and targeted demand management and customer engagement strategies.

This study sought to develop a next-generation water management system that combines advanced digital metering technology with machine learning to provide customers and water utilities with a breakthrough in household-scale water management. This breakthrough system (Autoflow) provides a range of functions including autonomous water end-use disaggregation, demand forecasting and customer-specific efficiency recommendations.

Keywords: Machine learning, digital metering, water end-use.

\section{INTRODUCTION}

Extensive research has demonstrated the benefit of combining advanced metering technologies and analytics in facilitating demand management solutions and other water business improvements (Britton et al. 2013; Nguyen et al., 2015; Cominola et al., 2015, 2018).

Autoflow (Nguyen et al., 2018) disaggregates residential water consumption into eight consumption categories including: shower, tap, clothes washer, dishwasher, toilet, bathtub, irrigation and evaporative air cooler. This outcome is achieved through the application of machine learning techniques including the Hidden Markov and Probabilistic Models combined with Deep Learning.

Autoflow has achieved a breakthrough classification accuracy of up to $95 \%$. The user friendly, cloud- based interface provides customers with timely access to their water consumption, a wide range of reports, and the ability to set future consumption targets and obtain automated water and energy conservation advice.

Water usage data was sourced from approximately 500 residential households fitted with a digital meter and data logger and located across several Australian cities. The digital meters provided sufficient flow resolution (0.01-0.02 $\mathrm{L} /$ pulse recorded in five or ten second increments) to facilitate micro- component disaggregation (i.e. individual end-uses).

Each household participated in an appliance audit to record appliance characteristics and a socio- demographic survey. This information was used to undertake the primary end-use disaggregation process for the development of a training dataset for the Autoflow machine learning system.

The latest version of the Autoflow system was developed through an Australian Research Council (ARC) Linkage Project involving Yarra Valley Water, City West Water, South East Water, Aquiba, Griffith University and University of Technology, Sydney.

\section{NEXT GENERATION SMART METERING SYSTEM DEVELOPMENT
OF AUTOFLOW}

Digital metering technology united with advanced data analytics enables a true paradigm shift in hydro- informatics. This approach can successfully augment water information provision to customers and water businesses (Stewart et al. 2010).

The aim of the project was to develop a breakthrough machine learning system for residential water end-use 
classification, customer feedback and enhanced urban water management.

In addition, the outputs were to be made available to customers and water businesses via a web-portal or mobile phone application. Staged development of the Autoflow system has been previously published (Nguyen et al. 2013, 2014, and 2015).

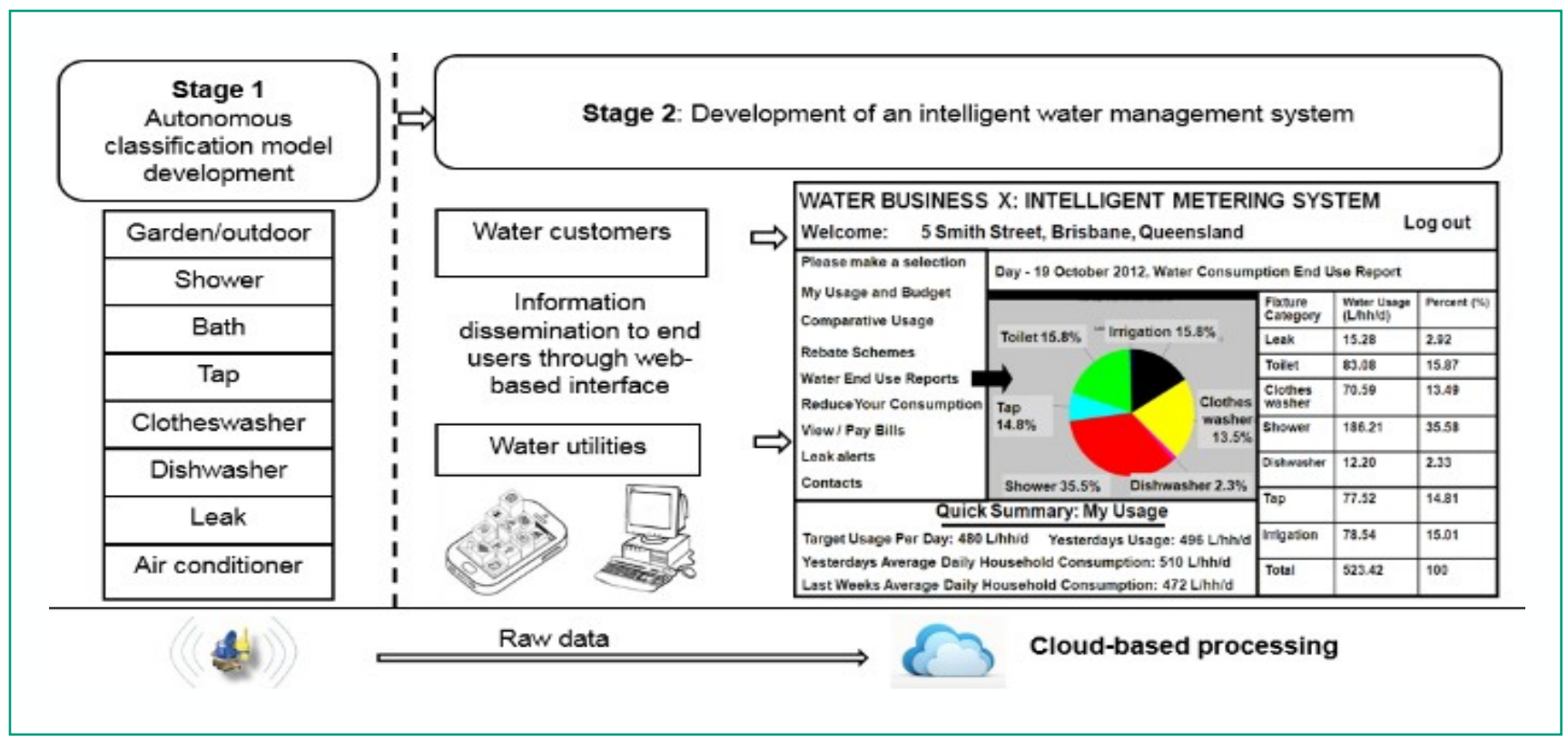

Figure 1. Overview of proposed autonomous and intelligent water management system

\section{Development process stages}

Figure 1 summarises the key research stages in Autoflow development and their implications for urban water management:

Stage 1: Develop a model that autonomously disaggregates water flow into a registry of water end-use events.

Stage 2: Develop a user-friendly, cloud-based web and smartphone application for consumers and water businesses.

The system allows individual consumers to log into their user-defined water consumption web page. This page allows customers to view their daily, weekly, and monthly consumption tables and charts on consumption for each end-use category (e.g. leaks, clothes washer, shower and irrigation). It can also rapidly alert customers to leaks rather than waiting for their quarterly bill.

The system can provide water end-use reports to water businesses for properties or suburbs, enabling more targeted demand management actions, improved demand forecasting and optimised asset modelling.

\section{Machine learning techniques applied to develop Autoflow}

Autoflow relies on advanced data analytics techniques to classify consumption into end-use categories.

Techniques employed include Hidden Markov Model (HMM), Dynamic Time Warping (DTW) Algorithm, Self-Organising Map (SOM), Deep Learning, and frequency analysis. These techniques have been successfully applied to develop an autonomous and intelligent system for residential water enduse classification.

The classification process used in Autoflow is presented in Figure 2. The first disaggregation stage involved separation of single events and combined events using HMM (Nguyen et al., 2013).

Following this, HMM, DTW, SOM, Deep Learning and time-of-day probability are applied to assign all remaining events into end-use categories (see Nguyen et al., 2013, 2014, 2015). 


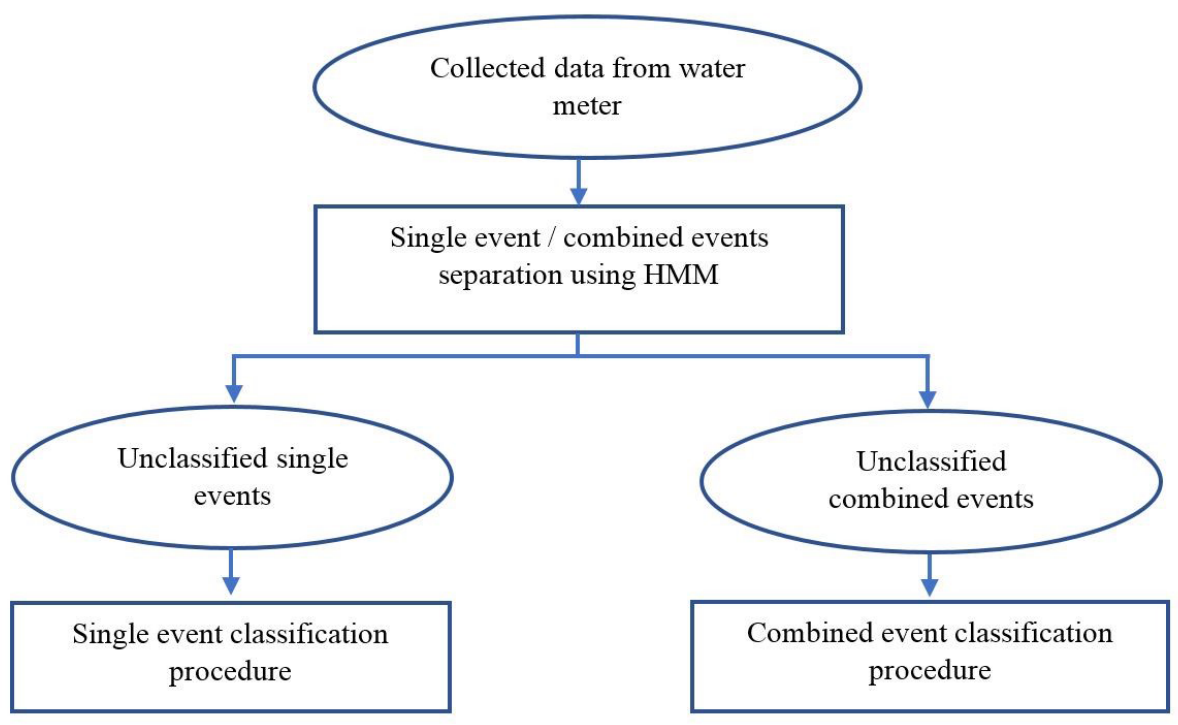

Figure 2. Schematic flow chart of autonomous water end-use pattern recognition system processing steps

\section{MODEL VERIFICATION}

\begin{tabular}{|c|c|c|c|c|}
\hline End Use & \multicolumn{4}{|c|}{ Number of Home } \\
\hline Category & Accuracy $>90 \%$ & $85-90 \%$ & $80-85 \%$ & AV $(\%)$ \\
\hline C. Washer & 118 & 68 & 14 & 93.2 \\
\hline Dishwasher & 60 & 33 & 27 & 94.2 \\
\hline Cooler & 11 & 13 & 8 & 88.6 \\
\hline Toilet & 38 & 135 & 28 & 92.8 \\
\hline Tap & 29 & 149 & 28 & 88.4 \\
\hline Shower & 160 & 26 & 14 & 85.4 \\
\hline Bathtub & 0 & 13 & 85 & 78.5 \\
\hline Irrigation & 0 & 0 & 36 & 75.9 \\
\hline
\end{tabular}

Table 1: Autoflow accuracy testing using testing dataset of 200 homes 
To evaluate system accuracy, testing was undertaken using data from 200 residential dwellings located across Australia. Achieved accuracy (Table 1) averaged $88.6 \%$, with the maximum of $94.2 \%$ for dishwasher and minimum of $75.9 \%$ for irrigation.

This verification process revealed common classification errors associated with disaggregating clothes washer, dishwasher and evaporative air cooler events.

The fundamental predictor of error was the presence of end uses with similar cycle times. With respect to clothes washers, $5.3 \%$ of the events were misclassified to dishwasher, $2.1 \%$ were to evaporative air cooler, and the remaining $1.4 \%$ were misclassified to tap and toilet.

Misclassification of dishwashers and evaporative air conditioners to clothes washer were $8.5 \%$ and $7.9 \%$, respectively.

Figure 3 provides two metrics of model testing results. Figure $3 \mathrm{a}$ (a confusion matrix) presents the number of events per category against correct classification for each end use. In Figure 3b, precision and recall are presented to express the obtained results in Figure 3a more scientifically.

\begin{tabular}{|c|c|c|c|c|c|c|c|c|}
\hline \multirow{7}{*}{ 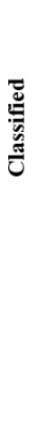 } & \multirow{7}{*}{$\begin{array}{l}\text { Clothes washer } \\
\text { Dishwasher } \\
\text { Toilet } \\
\text { Evaporative cooler } \\
\text { Shower } \\
\text { Tap } \\
\text { Irrigation }\end{array}$} & 1598 & 44 & 21 & 29 & 21 & 16 & 0 \\
\hline & & 92 & 813 & 15 & 34 & 16 & 21 & 2 \\
\hline & & 34 & 5 & 1394 & 31 & 23 & 68 & 0 \\
\hline & & 27 & 3 & 16 & 355 & 18 & 20 & 0 \\
\hline & & 6 & 5 & 39 & 0 & 1041 & 23 & 20 \\
\hline & & 5 & 51 & 21 & 38 & 17 & 1867 & 6 \\
\hline & & 0 & 0 & 0 & 0 & 4 & 7 & 35 \\
\hline
\end{tabular}

\section{a. Confusion matrix of testing results}

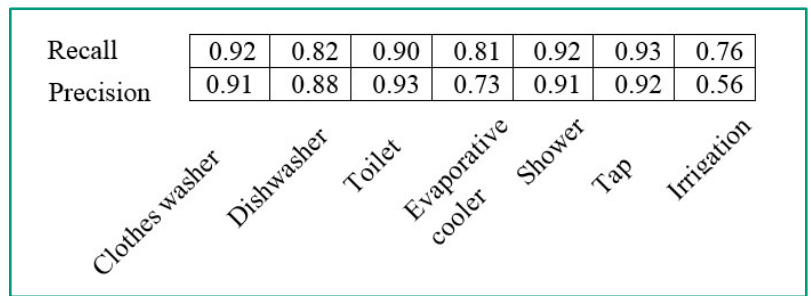

b. Precision and recall of testing results Figure 3 . Overall system testing result matrix

\section{AUTOFLOW CLOUD-BASED SYSTEM DEVELOPMENT}

To facilitate the widespread implementation of Autoflow $\odot$, a prototype cloud-based platform was developed to provide customers with a tool to monitor and manage their water consumption.

The main output from Autoflow (Figure 4) contains a list of descriptive statistics data on each end-use category. These statistics include: the average and mean values of volume, duration and flow rate. Other useful functionalities include the ability to "Set Target" and "Reduce Consumption".

\section{Set target}

To enable better household water, a function called "Set target" was developed. The "set target" function allows customers to monitor their accumulating consumption as it increases towards their set target.

Through the analysis of water consumption behaviour from previous periods, Autoflow performs a demand forecasting routine to generate a predicted consumption for the household for the forecast period.

Based on this information, a customer would be able to set a target for their future consumption limit and have the system send notifications when the amount of consumed water has reached, or is approaching, a certain threshold.

\section{Reduce consumption}

The "reduce consumption" module, which is still under development, will provide customers (on an opt-in basis) with customised efficiency advice for their home (Figure 6).

This Recommender System module draws upon knowledgebased analysis of customer usage patterns to undertake the following three main tasks:

- Analyse water consumption behaviours for each customer property;

- Synthesise consumption data in order to make customised recommendations based on the obtained consumption habits for each property; and

- Determine the extent to which customers have adopted the proposed recommendations through changed behaviours. 


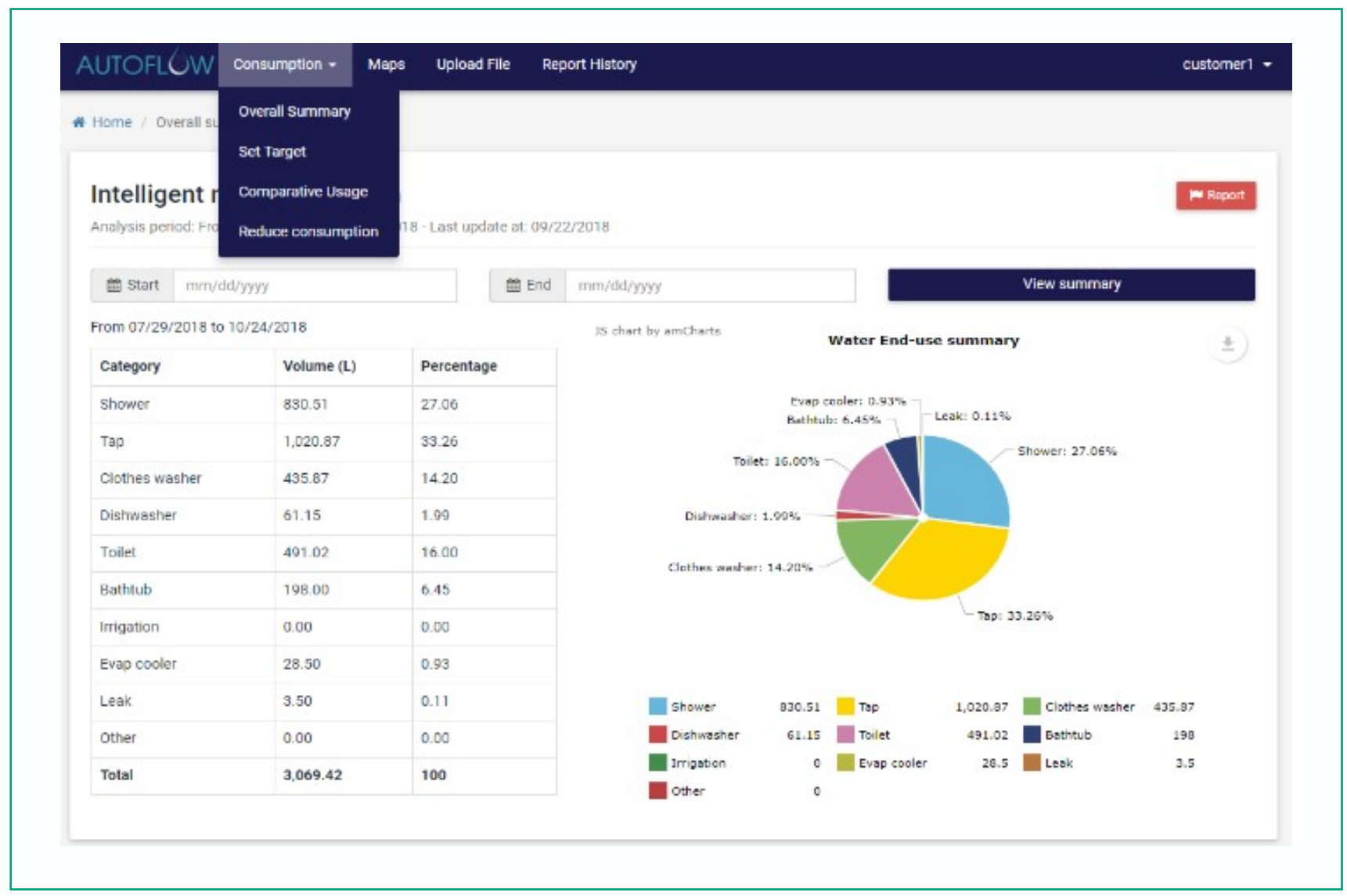

Figure 4. Cloud-based system main user interface

\section{NEXT GENERATION DIGITAL UTILITY BENEFITS}

Autoflow offers a range of benefits for consumers and digital water businesses including:

- The ability to view timely water consumption and statistical reports including comparisons with other households with similar demographic patterns; detailed water end use disaggregation; and customised demand management recommendations to help reduce consumption.

- Customer alerts when water demand is uncharacteristic (e.g. water leak in home).

- Efficiency recommendations for household water using appliances.

- Monitoring of total and disaggregated water consumption in a particular service area, district metered area or water supply zone.

- More accurate water balances including consumption and network leakage events.
- Better information to assist water supply planning engineers and demand management planners to forecast consumption and asset characteristics. This level of information would help to defer infrastructure augmentations or minimise asset size (and cost) (e.g. Gurung et al. 2014a); reduce pumping requirements and associated electricity costs (Dejan, 2011); reduce pipe bursts and network leakage (Girard and Stewart, 2007); and extend the pipe network asset life cycle (Gurung et al. 2014b).

- Provide an opportunity for water companies to engage more effectively with their customers and to create sustained goodwill. 


\section{CONCLUSION}

This paper provides a summary of the development process for the Autoflow software. This paper demonstrates the benefits of industry collaborative research to develop next generation digital utility solutions for the water industry.

Further work is planned to develop and validate the cloudbased Autoflow software and to conduct field trials with industry partners. The team is also exploring the development of self-learning algorithms to ensure that the Autoflow software is adaptable to new water end-use profiles and changing customer behaviours.

Finally, the team acknowledges the water-energy nexus and are starting to also embark on a digital multi-utility R\&D agenda (Stewart et al. 2018).

\section{ACKNOWLEDGEMENTS}

The authors greatly acknowledge and appreciate the kind support from the Australian Research Council (ARC) Linkage Project (LP160100215) and funding from the industry partners, including Yarra Valley Water, City West Water, South East Water, and

Aquiba. Special thanks to the University of Technology (UTS), Sydney, also a partnered investigator to this grant, for providing useful advice and support during the project.

\section{REFERENCES}

Britton, T.C., Stewart, R. A., \& O'Halloran, K. R. (2013). Smart metering: enabler for rapid and effective post meter leakage identification and water loss management. Journal of Cleaner Production, 54, 166-176.

Cominola, A.; Giuliani, M.; Piga, D.; Castelletti, A.; Rizzoli, A.E (2015) Benefits and challenges of using smart meters for advancing residential water demand modeling and management: A review. Environmental Modelling \& Software. 72, 198-214.

Cominola, A.; Giuliani, M.; Castelletti, A.; Rosenberg. D.E.; Abdallah, A.M. (2018) Implications of data sampling resolution on water use simulation, end-use disaggregation, and demand management. Environmental Modelling \& Software. 102, 199-212.

Dejan, C. (2011) Scheduling pump operation to save energy coast. Proceedings of Water and Energy in Changing Climate. September 26-29, 2010, Pittsburgh, USA.

Girard, M. and Stewart R.A. (2007) Implementation of Pressure and Leakage Management of the Gold Coast: Case Study. Journal of Water Resources Planning and Management, 133(3), 342-350.
Gurung, T.R., Stewart, R.A., Beal, C.D., Sharma, A.K. (2014a) Smart meters for enhanced water supply network modelling and infrastructure planning. Resources, Conservation and Recycling, 90, 34-50.

Gurung, T.R., Stewart, R.A., Beal, C.D., Sharma, A.K., (2014b) Smart meter enabled water end- use demand data: platform for the enhanced infrastructure planning of contemporary urban water supply networks. Journal of Cleaner Production, 101, 125-137.

Nguyen, K.A., Stewart, R.A. and Zhang H. (2013a). Development of an intelligent model to categorise residential water end use events. Journal of Hydro-Environment Research, 7(3), 182-201.

Nguyen, K.A., Zhang, H., and Stewart, R.A. (2013b). Intelligent pattern recognition model to automate the categorisation of residential water end-use events. Journal of Environment Modelling and Software, 47(5), 108-127.

Nguyen, K.A., Stewart, R.A. and Zhang H. (2013c) Development of an autonomous and intelligent system for residential water end-use classification, PhD Thesis, Griffith University.

Nguyen, K.A., Stewart, R.A. and Zhang H. (2014). An autonomous and intelligent expert system for residential water end-use classification. Journal of Expert Systems with Application, 41(2), 342- 356.

Nguyen, K.A. Stewart, R.A. Zhang, H. Jones, C. (2015) Intelligent autonomous system for residential water end use classification: Autoflow. Applied Soft Computing, 31(4), 118131.

Nguyen, K.A., Stewart, R.A., Zhang H., O. Sahin (2018). Reengineering traditional urban water management practices with smart metering and informatics. Environmental Modelling and Software 35, 344-356.

Nguyen, K.A., Stewart, R.A., Zhang H., O. Sahin (2018). Reengineering traditional urban water management practices with smart metering and informatics. Environmental Modelling and Software 35, 344-356.

Stewart, R. A., Willis, R., Giurco, D., Panuwatwanich, K., Capati, G., (2010). Web- based knowledge management system: linking smart metering to the future of urban water planning. Australian Planner, 47, 66 - 74.

Stewart, R.A., Nguyen, A.K., Beal., C., Zhang, H., Sahin, O., Bertone, E., Vieira, A.S., Castelletti, A., Cominola., A., Giuliani, M., Giurco, D., Blumenstein., M., Turner, A., Liu, A., Kenway,S., Savic, D.A., Makropoulos, C., Kossieris, P. (2018) Integrated intelligent water-energy metering systems and informatics: Visioning a digital multi-utility service provider. Journal of Environment Modelling and Software, $105,94$. 


\section{THE AUTHORS}

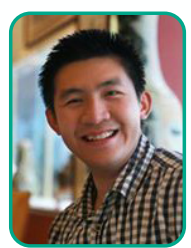

\section{Dr Khoi Nguyen}

Khoi Nguyen is a research fellow at Griffith University under the Griffith School of Engineering. He holds a Bachelor in Civil Engineering and $\mathrm{PhD}$ in water resources engineering from Griffith University. He has a current research focus Artificial Intelligence, Machine Learning, Embedded System Development and Blockchain technology.

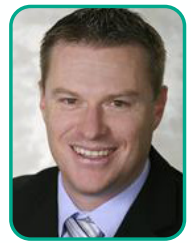

\section{Prof Rodney Stewart}

Rodney Stewart is a Professor and Deputy Head of School (Research) in the School of Engineering and Built Environment based at Griffith University, Australia. Professor Stewart is an expert in engineering, construction and environmental engineering and management research.

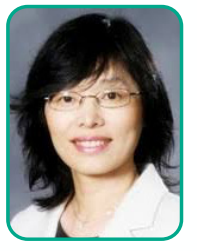

\section{Prof Hong Zhang}

Hong Zhang is a professor at School of Engineering and Built Environment. Her research interests are primarily in the fields of water resource engineering (flooding, river sediment transport, water quality and dynamics in lakes and ponds and groundwater flow) and the coastal/ocean dynamics (circulations, wave dynamics, mixing processes, wavestructure-soil interactions).

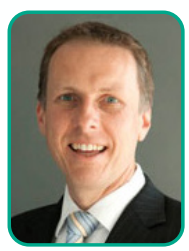

\section{Prof Damien Giurco}

Damien Giurco is currently the Director (Innovation) at the Institute for Sustainable Futures at UTS. Concurrently, he is Professor of Resource Futures, team leader for the research areas of Resources and Energy. His research interests span the minerals, energy and water sectors; industrial ecology and sustainable consumption and production.

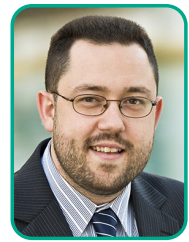

\section{Prof Michael Blumenstein}

Professor Michael Blumenstein is currently the Associate Dean (Research Strategy and Management) in the Faculty of Engineering \& IT at UTS. He is a nationally and internationally recognised expert in the areas of automated Pattern Recognition and Artificial Intelligence.

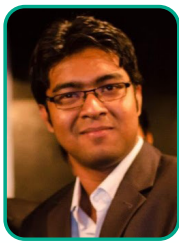

\section{Mr Shamsur Rahim}

Shamsur Rahim is currently a Ph.D. student at the University of Technology Sydney. His research interest includes Data Science, Big Data, Data Mining, and Machine Learning. 